\title{
RELAÇÕES INTERPESSOAIS NA UNIVERSIDADE: O QUE PENSAM ESTUDANTES DA GRADUAÇÃO EM PSICOLOGIA?
}

\section{Adriana Benevides Soares}

Universidade Salgado de Oliveira

Universidade do Estado do Rio de Janeiro

Gil Gomes
Universidade Salgado de Oliveira

Fátima de Almeida Maia

Universidade Salgado de Oliveira

\section{Clystine Abram Oliveira Gomes}

Universidade Salgado de Oliveira

Marcia Cristina Monteiro

União das Instituições de Ensino de São Paulo

\begin{abstract}
Resumo
As relações sociais na universidade são importantes para a adaptação, vivência e alcance de resultados acadêmicos. Este artigo teve como objetivo identificar como os estudantes universitários percebem suas vivências em situações interpessoais no espaço acadêmico. Utilizou-se Grupo Focal para coletar os dados e a Análise de Conteúdo para categorizar e analisar as falas dos estudantes. Participaram 13 estudantes do curso de Psicologia de uma universidade pública da cidade do Rio de Janeiro. Os resultados encontrados permitiram a categorização de situações consideradas como fáceis e difíceis. Nas situações consideradas difíceis, percebeu-se as dificuldades do estudante em lidar com as relações interpessoais. No que diz respeito à relação professor-aluno, foram identificadas dificuldades com a didática do professor. Entre as situações elencadas como fáceis, destaca-se: alunos que admiram seus professores, a tolerância com as diferenças, a socialização e a aceitação para trabalhar com colegas.
\end{abstract}

Palavras-chave: grupos focais; relações interpessoais; estudantes universitários; psicologia.

\section{INTERPERSONAL RELATIONS IN UNIVERSITY: WHAT DO UNDERGRADUATED STUDENTS IN PSYCHOLOGY THINK?}

\begin{abstract}
Social relations at the university are important for adaptation, experience and academic results. This article aims to identify how college students perceive their experiences in interpersonal situations in academic space. We used focus group to collect the data and content analysis to categorize and analyze the speech of the students. Participants were 13 psychology students from a public university in Rio de Janeiro city. The results allowed the categorization of situations as easy and difficult. Concerning difficult situations, we perceived the students' difficulties in dealing with interpersonal relationships. Regarding the teacher-student relationship, difficulties were identified with the teacher's didactics. As situations listed as easy, we highlight the students who admire their teachers, the tolerance of differences, socialization, and acceptance to work with colleagues.
\end{abstract}

Keywords: focus groups; interpersonal relationships; college students; psychology. 


\title{
RELACIONES INTERPERSONALES EN LA UNIVERSIDAD: ¿QUÉ PIENSAN LOS ESTUDIANTES DE LA GRADUACIÓN EN PSICOLOGÍA?
}

\begin{abstract}
Resumen
Relaciones sociales en la universidad son importantes para adaptación, experiencia y el alcance de los resultados académicos. Este artículo tiene como objetivo identificar cómo los estudiantes universitarios perciben sus experiencias en situaciones interpersonales en el espacio académico. Se utilizó focales para reunir los datos y el análisis de contenido para categorizar y analizar los discursos de los estudiantes. Participaron 13 estudiantes de la carrera de Psicología de una universidad pública en la ciudad Río de Janeiro. Resultados permitió la categorización de las situaciones consideradas de fácil y difícil. En situaciones consideradas difíciles ve las dificultades en el trato con las relaciones interpersonales. En relación con el profesor - estudiante dificultades de relación se han identificado con la metodología de la enseñanza. Entre las situaciones enumeradas como fácil es alumnos que admiran a sus maestros, la tolerancia puntas de las diferencias, la socialización y la aceptación de trabajar con colegas.
\end{abstract}

Palabras clave: grupos focales las relaciones interpersonales; estudiantes universitarios; psicología.

\section{INTRODUÇÃO}

$\mathrm{Na}$ sociedade moderna, o processo social demanda dos profissionais a construção de relações interpessoais que satisfaçam as necessidades das pessoas envolvidas na interação. Essa perspectiva pode facilitar e melhorar as relações que ocorrem no processo de formação profissional ainda na universidade, destacando que a utilização das habilidades sociais dos envolvidos no contexto acadêmico é entendida como condição básica para gerar aprendizagem e solucionar demandas sociais e interpessoais (Barreto, Pierre, Z. A. P. Del Prette, \& A. Del Prette, 2004). Nesta perspectiva, é importante ressaltar que a formação universitária se mostra comprometida em preparar o aluno para atender às necessidades de um mercado competitivo e com regras que vão na contramão de convivências que primam pelo encontro de si e do outro (Ferreira, 2011).

As relações sociais que se concretizam na universidade são entendidas por vários autores como importantes para a adaptação, vivência e alcance de resultados acadêmicos pretendidos pelos estudantes (Barreto et al., 2004; Iturra, Goic, Astete, \& Jara, 2012; Soares \& Gomes, 2013). Por adaptação acadêmica, entende-se as diversas tarefas e exigências no âmbito pessoal, social e escolar que compõem a dinâmica do estudante no Ensino Superior (Fernandes, 2011). A vivência acadêmica, segundo Almeida, Soares e Ferreira (2000), engloba quatro dimensões: acadêmica, pessoal, social e vocacional. A dimensão acadêmica refere-se ao novo ritmo de trabalho e estratégias de aprendizagem para lidar com a nova modalidade de ensino. A pessoal está relacionada ao desenvolvimento de aspectos como autoestima, autoconhecimento, identidade e a percepção de mundo. A social refere-se a padrões mais maduros de relacionamento com familiares, colegas, professores e pessoal administrativo. A vocacional envolve o engajamento com o curso e a futura profissão. Neste 
sentido, as dimensões envolvem comportamentos desejados pelos estudantes como tirar boas notas nas provas, fazer novas amizades, participar de eventos sociais, pertencer ao núcleo estudantil e que podem estar relacionados à utilização, com destreza, de um bom repertório de habilidades sociais ( $A$. W. Pagotti \& G. A. Pagotti, 2005; Soares \& Gomes, 2013).

Segundo Z. A. P Del Prette e A. Del Prette (2010a), as habilidades sociais podem ser entendidas como comportamentos que produzem resultados reforçadores tanto para o indivíduo como para o grupo, sendo que comportamentos coercitivos e agressivos não são considerados como socialmente competentes. Para os mesmos autores, caso as habilidades sociais sejam utilizadas com competência social, podem produzir equilíbrio entre os envolvidos, gerando bem-estar e criando um ambiente encorajador para o ensino e o aprendizado. O contexto acadêmico exige dos estudantes competência em utilizar as suas habilidades sociais, principalmente em situações interpessoais consideradas de difícil manejo (Soares \& Del Prette, 2015).

O campus universitário pode reproduzir de forma mais intensa as demandas sociais encontradas no dia-a-dia. Nesse espaço, o estudante necessita realizar trabalhos em equipe, interagir com pessoas de diferentes características sociais e pessoais e com opiniões divergentes das suas na maior parte do tempo, o que pode explicar a formação de grupos de afinidades em sala de aula. A construção das relações com pares e outros personagens do contexto universitário demanda dos alunos habilidades sociais que os possibilitem respeitar as regras e normas pré-estabelecidas pelos grupos e subgrupos, caso contrário, podem experimentar reações adversas que, dependendo da intensidade, resultem em sentimentos de rejeição e, em casos mais extremos, em violências físicas ou verbais (Salles \& Silva, 2012).

Para Bartholomeu, Nunes e Machado (2008), a relação entre habilidades sociais e os processos de interação que uma pessoa pode apresentar ao longo de um contínuo se prolonga da compaixão a hostilidade. Os autores afirmam que graduandos que apresentam mais habilidades sociais tendem a ser atenciosos, compreensivos, empáticos e agradáveis com os colegas e os demais que compõem a comunidade universitária. Esses pesquisadores apontam também que as mulheres mais hábeis socialmente manifestam um maior autocontrole de agressividade em situações desagradáveis. Igue, Bariani e Milanesi (2008) ressaltam ainda que o âmbito interpessoal da vida do aluno ingressante, especialmente sua integração social, afeta diretamente seu compromisso com a instituição e com os estudos universitários.

Teixeira, Dias, Wottrich e Oliveira (2008) apontam que o companheirismo construído nas primeiras experiências na universidade é percebido como importante pelos alunos ingressantes, pois existe uma expectativa nos laços de amizades que se formarão no sentido de permitir aos estudantes compartilharem interesses, dificuldades, expectativas, facilitando a adaptação. Segundo os 
autores, a ausência do sentido de grupo pode ser motivo de desapontamento, pois frusta as expectativas de mudanças nas relações sociais com a entrada no Ensino Superior. Neste sentido, ao formarem grupos, a intenção dos estudantes está associada ao objetivo de se sentirem reciprocamente apoiados e trabalhar com mais liberdade com aqueles que acreditam possuir características parecidas com as suas. No entanto, essa estratégia pode resultar em algumas dificuldades para o aluno caso pretenda migrar para outros grupos. Segundo Z.A.P. Del Prette e A. Del Prette (2004), entrar ou sair de um grupo pode ser considerado uma situação interpessoal difícil e que exige a utilização de habilidades sociais bem elaboradas para executá-la.

Outro aspecto vinculado à formação de grupos se encontra na relação dos estudantes com a instituição de ensino. Na relação com a instituição, é comum que os alunos tenham que fazer valer os seus direitos e, agindo em grupos, podem se perceber mais fortalecidos para exigi-los. Segundo Polydoro, Primi, Serpa, Zaroni e Pombal (2001), os alunos passam por decepções e frustrações em relação à universidade ao longo de sua formação. Esse quadro pode contribuir sobre a continuidade ou desistência do curso e da instituição escolhida. Para Cunha e Carrillo (2005) é necessário que os alunos percebam boa vontade das instituições em atenderem as suas necessidades, caso contrário, podem experimentar sentimentos de indiferença e, com isso, dificultar ainda mais esse momento de transição que por si só já é carregado de entraves. Dessa forma, a pressão social do grupo em sua tomada de decisão é determinante (Z. A. P. Del Prette \& A. Del Prette, 2004).

Além da relação com a instituição, alunos têm também que se relacionar com os funcionários. A qualidade dessa interação pode se tornar um fator de estresse e mais um obstáculo a ser superado pelos estudantes. Todavia, Barreto et al. (2004) afirmam que as relações interpessoais estabelecidas no espaço acadêmico precisam satisfazer os envolvidos de maneira que resolvam o problema imediato e evitem consequências negativas no futuro. Pagotti e Pagotti (2005) identificaram que existe insatisfação dos estudantes em relação ao atendimento dos funcionários, que dificilmente recebem treinamento para conseguirem compreender e atender as necessidades apresentadas pelos alunos. $\mathrm{O}$ investimento no treinamento dos funcionários que atendem diretamente os alunos deveria ser uma das prioridades institucionais.

No entanto, dentre as relações interpessoais estabelecidas na instituição de ensino, como fazer novos amigos, lidar com funcionários e gestores, a mais delicada acontece entre alunos e professores. Para Ferreira e Souza (2010) alguns docentes ainda ignoram esse fato e incorporam em sala de aula o papel de detentor do conhecimento e, assim, colocam o aluno no lugar de espectador passivo daquele que possui o conhecimento. A relação professor/aluno pode motivar o estudante a participar com mais engajamento nas atividades e oportunidades oferecidas pela instituição de ensino, além de maximizar o 
aproveitamento do tempo de cada componente curricular. (Santos \& Soares, 2011). O professor universitário é formador de opinião e serve de modelo de identidade para seus educandos, principalmente se o aluno estiver no final da adolescência ou princípio da vida adulta, tendo muito que a aprender sobre si mesmo, sobre valores, sentimentos, interações e relações com os outros. Neste sentido, Gonçalves, Leite, Pavinato, \& Leite (2009) ressaltam que, diante de conflitos na relação professor-aluno, os estudantes tendem a mostrar insatisfação com os conteúdos e dificuldades no processo de aprendizagem. Os autores acrescentam que as relações interpessoais saudáveis permitem uma cumplicidade entre aluno e professor, proporcionando um convívio baseado na confiança, na troca de experiências e com isto, provavelmente, contribuindo para o processo de aprendizagem do estudante.

Apesar das dificuldades encontradas em algumas relações interpessoais, como saber lidar com opiniões diferentes, receber e fazer críticas, o estudante percebe determinadas situações como de fácil manejo (Soares \& Del Prette, 2015). Supostamente, as relações interpessoais consideradas fáceis podem ir ao encontro das habilidades sociais do aluno ou da outra pessoa envolvida na relação. Segundo Iturra et al. (2012) o aluno que portar e for capaz de utilizar um repertório de habilidades sociais bem elaboradas, pode desenvolver interações saudáveis e até mesmo administrar e resolver conflitos inerentes ao ambiente acadêmico. Silva (2012) destaca que o bem-estar do aluno pode ser considerado um indicador de saúde mental do estudante, além de ser essencial para o desenvolvimento pessoal, da aprendizagem, da satisfação e sucesso acadêmico. Nesse sentido, fazer amizades de maneira saudável, traduzidas em contribuição recíproca, legitimando as próprias necessidades e as do outro, revelando afeto e admiração que podem ser percebidos como agradáveis pelos envolvidos (Coll \& Collomina, 1996; A. Del Prette et al., 2004). Alguns alunos, entretanto, encontram dificuldades em construir amizades mais próximas, tendo por sua vez que vencer a timidez. Nesse caso, a utilização de recursos virtuais (facebook, whatsapp), possibilitam novas amizades sem a necessidade de se expor aos outros num primeiro momento (Bariani \& Pavani, 2008).

Diante do exposto, o presente estudo tem como objetivo verificar e conhecer, através da realização de um grupo focal, quais são as relações interpessoais que os estudantes vivenciam como fáceis e difíceis no espaço acadêmico com pares, professores, gestores e funcionários da instituição de Ensino Superior. Desta forma, será possível gerar insumos para reflexões críticas que possibilitem intervenções junto à realidade encontrada no contexto acadêmico em benefício dos estudantes. 


\section{MÉTODO}

O método de grupo focal tem como objetivo coletar dados para a investigação a partir da relação construída no grupo, possibilitando a discussão da temática proposta (Kind, 2004). Segundo Gatti (2005), o grupo focal é uma técnica que possibilita o acesso as formas de linguagens, expressões, representações, valores, crenças e preconceitos, traços em comum, características compartilhadas por um grupo, gerando novos debates pela análise ou problematização de uma ideia através de um processo argumentação entre os participantes.

\section{Participantes}

Participaram do estudo 13 estudantes do 30 período de Psicologia de uma Universidade pública da cidade do Rio de Janeiro, sendo dois do sexo masculino, com idades variando de 19 a 31 anos, média de idade de 22 anos $(D P=5,11)$, sendo a maioria de solteiros $(84,62 \%)$ e pertencente à classe social B2, conforme apresentado na Tabela 1.

Tabela 1. Descrição dos participantes por idade, sexo, estado civil e classe social

\begin{tabular}{ccccc}
\hline Participantes & Idade & Sexo & Est.Civil & $\begin{array}{c}\text { Classe } \\
\text { Social }\end{array}$ \\
\hline P1 & 20 & M & S & B2 \\
P2 & 20 & F & S & B2 \\
P3 & 36 & F & D & B2 \\
P4 & 20 & F & S & C1 \\
P5 & 19 & F & S & B1 \\
P6 & 19 & F & S & B2 \\
P7 & 21 & F & S & B2 \\
P8 & 19 & F & S & B2 \\
P9 & 19 & F & S & C1 \\
P10 & 23 & F & S & C1 \\
P11 & 20 & F & S & B2 \\
P12 & 19 & F & S & - \\
P13 & 31 & M & C & - \\
\hline
\end{tabular}


Procedimentos de coleta de dados

A coleta de dados do grupo focal se deu através da técnica de Backes, Colomé, Erdmann e Lunardi (2011). Foi pedido aos participantes que se expressassem livremente sobre as relações interpessoais no ambiente acadêmico. Os participantes foram selecionados por conveniência e liberação de alguns professores do curso de Psicologia. Para identificar o nível socioeconômico e a estratificação das famílias em seis classes econômicas decrescentes (A1, B1, B2, C1, C2, DE) foi utilizado o Questionário Critério Brasil (ABEP, 2015).

\section{Procedimentos éticos}

Todos os participantes assinaram o Termo de Consentimento Livre e Esclarecido (TCLE) e o estudo foi aprovado pelo Comitê de Ética da Universidade (parecer n.0 689.307/14).

\section{Procedimentos de análise de dados}

As discussões do grupo focal sobre as relações interpessoais foram gravadas e transcritas integralmente e posteriormente foi feita uma categorização do texto segundo a Análise de Conteúdo. Essa análise consiste na exploração do material em que se catalogam as falas encontradas (Bardin, 2009). A análise cuidadosa das falas dos participantes possibilitou significações trazidas nas discussões no grupo de voluntários.

\section{RESULTADOS E DISCUSSÃO}

As falas dos estudantes entendidas como mais significativas pelos pesquisadores foram analisadas e categorizadas. Na relação aluno/aluno, encontraram-se quatro situações consideradas difíceis pelos participantes. A primeira categoria identificada como difícil foi a intolerância com as diferenças. Desse modo, a igualdade de características sociais e raciais é vista como facilitador da formação dos grupos dentro da sala de aula nos primeiros períodos de faculdade, quando os alunos acham que conviver com pessoas com o mesmo status social ajuda a manter boas relações interpessoais e melhorar o trabalho em equipe. Conforme trazido pelos participantes:

"Acho que nicho social. Se a pessoa for do seu mesmo status social, facilita. A pessoa da sua mesma etnia facilita. Racial, facilita. Se você é uma pessoa também de cota, facilita também de vocês interagirem".

Não obstante, as diferenças sociodemográficas e das características pessoais podem se constituir em dificuldades para a boa convivência entre os subgrupos que se formam em sala de aula. $O$ entendimento de que a semelhança das características pessoais e sociodemográficas são importantes para uma boa relação pode resultar em atitudes com consequências danosas ao próprio aluno. Para Salles e Silva (2012), os estereótipos e as diferenças entre os 
alunos no espaço acadêmico podem contribuir para desencadear situações de violência na interação entre os alunos. Para os mesmos autores, classificar o outro como diferente pode provocar conflitos que geram problemas de relacionamento interpessoal conduzindo inclusive à violência e ao desprezo por parte dos demais.

A formação de "panelinhas" foi a segunda categoria identificada e que impede a relação do estudante com determinados colegas da classe e parece ser uma queixa recorrente que, apesar do mal-estar provocado, pode ser a estratégia utilizada pelos iniciantes para se perceberem apoiados e protegidos. Conforme trazido por um dos participantes:

"De mim não, do próprio grupo, depois que ele se fecha é raro você conseguir entrar lá e fazer parte disso e dialogar com as suas questões".

Dessa forma, os estudantes habitualmente se fecham em grupos e dificultam 0 ingresso de novos componentes. Aparentemente, os alunos encontram dificuldades em formar novas alianças e se acomodam com as regras veladas pelas "panelinhas", evitando transitar com mais desenvoltura de uma equipe para outra. Esse comportamento pode dificultar o fluxo de informações entre os docentes e prejudicar a criação de novas ideias em relação ao outro. Para A. Del Prette et al. (2004) os grupos possuem características próprias de comportamentos e normas que são aceitas e valorizadas por seus membros. A forma como o sujeito interpreta os componentes determina a quantidade de investimento despendido para sua inserção no grupo. O ingresso de novos participantes é franqueado quando se consegue se auto-observar e adequar os comportamentos, flexibilizar atitudes, concepções e valores conflitantes com a cultura do grupo.

A dificuldade de comunicação interpessoal foi a terceira categoria e também impede que os estudantes se comuniquem com mais liberdade e se aprofundem no conhecimento e no entendimento dos colegas de classe. Conforme exposto pelos alunos:

"É, mas o contato é também bem superficial, a gente não tem realmente aquele contato".

Mesmo com o aparente desejo de ampliar o seu ciclo de amizades, parece que encontram dificuldades na comunicação interpessoal. Portanto, falta aos estudantes as habilidades necessárias para se aproximarem do outro e iniciarem conversas. Diante disso, tentam fazer e manter amizades utilizando métodos e estratégias que descartem a necessidade de se exporem a seus pares. Para A. W. Pagotti e G. A. Pagotti (2005), as principais preocupações dos estudantes universitários estão relacionadas à capacidade em atender às demandas acadêmicas, tirar boas notas, resolver conflitos no ambiente universitário e também fazer e manter amizades consistentes com os colegas. No entanto, Yazedjian, Purswell, Sevin e Towes (2007) sustentam que no Ensino Superior 
alguns estudantes se focam em de fazer novas amizades e a se colocar à disposição dos colegas. De algum modo, os estudantes demonstram dificuldades e pouca competência social para construir relações interpessoais adequadas dentro do campus universitário.

Quanto às dificuldades de socialização, a quarta categoria identificada, parece que existe uma limitação em se colocar no lugar do colega e com isso compreender melhor as suas necessidades. Consideram essa habilidade difícil de praticar, porém fundamental para o exercício da profissão do Psicólogo. Como no exemplo trazido pelos participantes:

"Pior que isso é de repente ter dificuldade de empatizar, ter dificuldade de ver o ser humano numa situação limite e não sentir nada".

Os estudantes acreditam que a adequação das relações interpessoais com os seus pares poderia auxiliá-los no desenvolvimento de habilidades sociais que mais tarde, seriam úteis no exercício profissional. Portanto, os conflitos interacionais parecem ir além das relações interpessoais entre os estudantes no campus universitário. Aparentemente, existe a preocupação em interagir adequadamente com os futuros clientes no exercício da profissão. Sendo assim, o desenvolvimento das habilidades sociais parece ser negligenciado nos cursos de Psicologia. A. Del Prette, Z. A. P. Del Prette e Branco (1992), ao analisarem o curso de Psicologia e seu programa curricular, concluem que na formação dos Psicólogos as disciplinas não incluem o treinamento das habilidades sociais, apesar de serem fundamentais para a atuação profissional. Para os mesmos autores, o ambiente acadêmico é rico em possibilidades para o treinamento e desenvolvimento destas habilidades e se constitui em oportunidades para complementação da formação profissional do aluno.

$\mathrm{Na}$ relação do aluno/instituição, foram verificadas três categorias consideradas de difícil manejo pelos discentes. A primeira categoria levantada foi a insatisfação curricular entendida por eles como se os interesses da instituição estivessem fora de sintonia com os seus e é apontada como um agravante da dificuldade na relação do aluno com a instituição. Segundo uma fala do grupo:

"Nas universidades do Rio de Janeiro, UFRJ e UFF, têm muitas pessoas voltadas para a psicanálise eu sinto falta de ter outras trocas, nós tivemos TCC no $2^{\circ}$ período, a maioria dos nossos professores são psicanalistas".

$\mathrm{Na}$ visão dos estudantes, é importante que a universidade ofereça uma variedade de opções para facilitar as suas escolhas de atuação profissional. Considerando essa demanda, Polydoro et al. (2001) destacam que muitas das situações vivenciadas pelos alunos podem gerar frustrações e decepções, comprometendo sua maneira de perceber o curso escolhido. Para os mesmos autores, a integração dos jovens à universidade é baseada nas relações entre os alunos e a instituição, entretanto, faltam políticas no Brasil para garantir a 
permanência e o melhor aproveitamento dos alunos ao longo do Ensino Superior. Enfatizam que contar apenas com programas que ampliem o acesso do aluno à universidade não garante a continuidade e a qualidade da formação. Sendo assim, as instituições ainda falham em atender algumas necessidades do discente, sanando as dificuldades e garantindo a sua satisfação dos serviços prestados.

Talvez norteados por suas expectativas sobre o curso escolhido, os estudantes consideram que a grade curricular poderia ser mais adequada as suas primordialidades e proporcionar mais conhecimentos para sua formação profissional. Os alunos demonstram insatisfação em relação às matérias e apontam para a urgência em conhecerem diversas teorias da Psicologia Clínica e a visão de outros profissionais para que possam definir sua maneira de trabalhar futuramente com mais fundamentação teórica. Silva (2010) diz que a contratação de um corpo docente diversificado poderia suprir esta carência e, para que haja novas contratações, torna-se necessário uma política pública com este objetivo. Dentro dessa visão, no primeiro mandato do Governo Lula foi criado o Grupo de Trabalho Interministerial (GTI; Brasil, 2003) em 20 de outubro de 2003, órgão criado com o objetivo de analisar, reestruturar e democratizar as Instituições Federais de Ensino Superior (IFES). O documento "Bases para o Enfrentamento da Crise Emergencial das Universidades Federais e o Roteiro para Reforma Universitária Brasileira" foi criado pelo GTI para delinear a proposta de mudança. Neste documento uma cláusula enfoca a contratação por concurso público de novos funcionários: professores e servidores administrativos. Apesar da elaboração do documento, o cenário atual da educação superior pública no país não dá sinal de mudanças efetivas que possam garantir transformações que diminuam a evasão e que possibilitem um ambiente de qualidade aos discentes e docentes, promovendo o processo de ensino e aprendizagem almejado.

A segunda categoria identificada foi a indiferença da instituição. Os estudantes a percebem como forma de distanciá-los das tomadas de decisão, conforme discutido pelo grupo:

"Eu acho que a direção passa muito a ideia de que a gente tem poder na universidade, mas na prática não é bem isso".

Para os discentes, a ideia de que participam efetivamente das tomadas de decisão de assuntos que afetam diretamente seus interesses estão longe da realidade universitária. O resultado desse cenário é a inércia da instituição em solucionar os problemas que interferem no aprendizado do aluno. Em seu entendimento, o desinteresse da mesma em atender suas demandas gera insatisfação e falta de motivação para a maioria dos estudantes. Esse quadro merece ser tratado com mais cuidado e seriedade. Cunha e Carrillo (2005) apontam que as universidades precisam mudar seus conceitos em relação aos métodos e práticas de aprendizagem para que os discentes possam vivenciar o Ensino Superior com mais tranquilidade e produtividade, considerando que essa 
é uma fase do ensino que traz em seu bojo mudanças substanciais na vida dos jovens estudantes.

A terceira e última categoria levantada foi citada a desinformação, que pode provocar no aluno a percepção de ser preterido pela instituição. Esse sentimento fica mais evidente quando não são informados sobre eventos na universidade, principalmente, os que abordam temas que acreditam contribuir para ampliar à visão teórico-prática sobre a Psicologia e as suas áreas de atuação, conforme sinalizado nas falas dos participantes:

"Pra falar a verdade, esse seminário da Gestalt eu só fui saber depois que aconteceu".

O estudante considera importante a participação em eventos para a complementação de sua formação e reclamam da falta de divulgação deste tipo de atividade pela instituição de ensino. Teixeira et al. (2008), Cunha e Carrilho (2005) e Igue et al. (2008) corroboram com a visão dos estudantes e destacam que as situações vivenciadas na universidade são fundamentais para a formação dos mesmos. Para esses autores, além desse aspecto, conflitos com a instituição de ensino relacionado à falta de recursos didáticos poderiam ser solucionados com melhor comunicação entre o aluno e mais apoio psicológico da instituição, principalmente nos primeiros períodos do Ensino Superior.

Quanto à relação aluno-funcionário, foram encontradas somente duas categorias consideradas difíceis no entendimento dos discentes. A primeira categoria foi o descaso do funcionário em relação ao aluno que revela a dificuldade em ter suas demandas atendidas, aparecendo como queixa dos estudantes quando têm que procurar a secretaria para resolver algum problema acadêmico. Mais uma vez, os alunos entendem que os seus interesses na instituição são tratados de forma inadequada, segundo a fala do grupo:

"Eles meio que falam rápido, e 'despacham' a gente".

$\mathrm{Na}$ visão do discente, o funcionário parece ignorar as suas atribuições dentro da instituição e passam a tratar suas necessidades com indiferença. $O$ estudo de A. W. Pagotti e G. A. Pagotti (2005) também mostrou a insatisfação dos estudantes na relação com os funcionários diante do atendimento de suas demandas. Nesse cenário, os graduandos entendem que os funcionários não alcançam a importância de suas funções e são despreparados para se relacionar de maneira adequada com os alunos. Ressaltam que serviços como os da secretaria institucional são, em muitos casos, a porta de entrada e o elo mais rápido do aluno para obter informações e orientações sobre as questões acadêmicas. Polydoro, Primi, Serpa, Zaroni e Pombal (2001) destacam que a relação do estudante com a instituição de ensino é de fundamental importância para a tomada de decisão para dar continuidade à sua formação profissional.

A segunda categoria compreendida como de difícil manejo foi a arrogância do aluno em relação ao funcionário. Talvez como forma de revidar a percepção 
de tanta indiferença da instituição e de seus funcionários, os universitários busquem demonstrar a sua insatisfação tratando de maneira inadequada os funcionários de funções menos valorizadas, conforme apontado pelo grupo:

"Poxa, mas nós estamos aqui estudando Freud, Lacan, behaviorismo, e que tipo de contato pode-se ter com um funcionário assim"?

No entanto, cabe aos estudantes adequar a forma de reivindicar direitos. Nesse sentido, Barreto et al. (2004) apontam para a importância de relações que satisfaçam os envolvidos. Essa perspectiva pode melhorar e adequar as relações interpessoais que acontecem dentro das universidades. Os mesmos autores destacam que o desenvolvimento da competência social é requisito básico no processo de ensino aprendizagem, o que seria um dos princípios essenciais para resolver problemas dentro das organizações.

Nas relações difíceis entre os professores-estudantes, três categorias são reveladas. A primeira categoria levantada foi dificuldades com a didática do professor, evidenciando para os estudantes que o modo como o professor ensina não obedece às expectativas da turma. Na concepção do aluno, o professor utiliza técnicas incompatíveis com as suas formas de aprendizado, conforme exemplificada na fala do grupo:

"Parece que quando o professor fala a gente aprende mais, o slide deixa a gente engessada, a luz parece que hipnotiza a gente".

Os alunos se percebem excluídos da decisão do professor sobre o formato em apresentar a sua aula. Esse comportamento do professor pode resultar num distanciamento das capacidades e do interesse do discente em aprender a matéria. Ferreira e Souza (2010) destacam que a concepção do professor está associada à função de detentor do conhecimento, com forma de ensinar voltada à capacidade de memorização e centrada na transmissão de conteúdos descontextualizados e sem significação. Contrário a esse entendimento, Lener (2011) considera que a aprendizagem decorre da interação estabelecida entre educador-educando e no aproveitamento das demandas do ambiente no qual o indivíduo está em atividade. Assim, cada uma das partes envolvidas no processo de aprendizagem tem como objetivo favorecer e estabelecer conhecimentos que serão apreendidos e aplicados na prática profissional e na vida do cidadão, concretizando assim o objetivo do saber universitário. Portanto, construir aprendizado significativo que leve o indivíduo à reflexão, ao diálogo, à argumentação sem medo, pode auxiliar de forma positiva a relação entre professores e alunos (Santos \& Soares, 2011). Para Santos e Soares "a qualidade na relação professor-estudante no processo de formação parece ser decisivo, considerando que a aprendizagem é o que justificaria o encontro entre professor e estudantes" (2011, p.358). Portanto, a aprendizagem é o foco principal da relação professor-aluno e é no encontro desses dois atores que se justifica a aquisição de conhecimentos de forma saudável e desafiante para a formação de cidadãos ativos e autônomos. 
A segunda categoria diz respeito à dificuldade na condução de assuntos polêmicos, os estudantes entendem que o professor evita levantar e discutir assuntos conflitantes dentro de sala de aula, segundo a fala dos participantes:

"Quando o professor está na sala, a gente começa a querer esse tipo de discussão e já é logo dissolvido rapidamente por ele".

Para os alunos, tal comportamento limita a sua capacidade de refletir e fazer associações do seu cotidiano com o assunto que está sendo discutido. 0 professor é mediador dos conhecimentos socialmente acumulados, possibilitando, ao fim de todo o processo, que o aluno possa reelaborar o que foi ensinado e de expressar uma compreensão na prática do que foi aprendido. A ação pedagógica é mediadora e problematizadora dos conteúdos sistematizados, das vivências dos alunos e dos fatos sociais. Essa constatação vai ao encontro do estudo desenvolvido por Carrara e Betetto (2009), que apontam para a responsabilidade das instituições em educar o discente a agir com ética e cidadania e dentro dessa perspectiva, métodos de ensino que permitam praticar no seu dia a dia o que aprende no contexto acadêmico.

Finalmente, a terceira categoria levantada foi o desinteresse pela aula. Os estudantes entendem que existe uma contribuição deles por justificarem comportamentos inadequados em aula através dos métodos de ensino utilizados pelos professores, conforme discutido pelo grupo:

"Quem senta lá atrás, vai para o Facebook, nós estamos reclamando que a aula é corrida, mas dá tempo de ir para o Facebook".

Bariani e Pavani (2008) apontam que o falta de interesse do aluno pela aula pode estar associado a métodos de ensino que envolvam procedimentos e tarefas executadas pelo professor. Entretanto, os mesmos autores entendem que o estudante precisa assumir a responsabilidade por seus comportamentos em ter bom desempenho e se tornar um profissional qualificado. O interesse do aluno é crucial para que ocorra a aprendizagem, assim como a interação do estudante com os conteúdos que estão sendo propostos pelas diversas disciplinas que compõem a grade curricular. Essa conduta pode exercer peso considerável na sua decisão em participar de forma mais ou menos ativa das aulas.

Quanto às situações fáceis, foram encontrados três seguimentos e seis categorias consideradas fáceis. O primeiro segmento refere-se à relação alunoprofessor. A primeira categoria identificada foi a visão dos estudantes sobre debates e participação em sala de aula. Os professores que demonstram coerência em seus comportamentos e aceitam debater em sala de aula harmonizam a relação entre discentes e docentes e facilitam o aprendizado, como no exemplo da fala dos participantes:

"Eu sempre achei que ele cobrou na prova o que ele passou em sala de aula, independente do método".

Antunes (2001) destaca que armazenar a informação oferecida pelo professor é menos importante do que saber aplicá-la. Para o mesmo autor, é 
necessário que o aluno utilize o que aprendeu para solucionar problemas cotidianos. Apreender é associar as informações para a compreensão do mundo. O que o aluno aprende, precisa se estender para outros contextos. Precisa ser útil para ele em diversas situações, pois compreender envolve saber explicar, argumentar, relacionar, aplicar e extrapolar conhecimento. No entanto, a relação entre o ensino e a aprendizagem fica restrita à discussão desenvolvida em sala de aula, que é reduzida a criar significados. O mesmo autor acrescenta que o professor deve sempre acompanhar o processo para a construção do conhecimento e representar para os alunos o agente entre os objetos do saber e da aprendizagem. Dessa forma, os debates em aula poderiam se constituir na oportunidade de aplicação do conhecimento fora dos muros da universidade.

A segunda categoria levantada refere-se à admiração pelos professores. 0 desenvolvimento de relações de respeito e interesses mútuos pode facilitar e fazer com que alunos e professores se admirem reciprocamente. Segundo trazido pelos participantes:

"Eu ainda vou sequestrar aquele cara e colocá-lo no meu armário para falar comigo".

Sendo assim, a relação entre ambos e o aproveitamento das aulas pode fluir com mais harmonia na busca de seus objetivos. Para o estudante, é importante ter o professor como um modelo de profissional. O seu interesse em se qualificar para o mercado de trabalho está associado à admiração que sente por pessoas que entendem que podem contribuir com a sua trajetória para atingir esse alvo. Pode-se considerar que a admiração pelos docentes é capaz de motivar o aluno a gostar da disciplina e a se aproximar do professor. 0 bom relacionamento entre discente-docente favorece a práxis do professor e o processo de aprendizagem do aluno. Guimarães e Boruchovich (2004) destacam que a universidade é um espaço de socialização e aprendizagem. Portanto, o ambiente acadêmico e a maneira como são estruturadas as atividades são fundamentais para motivar e criar relações de ensino/aprendizagem adequadas aos objetivos de alunos e professores.

$\mathrm{Na}$ relação aluno com funcionário, segundo segmento, a categoria considerada fácil foi o respeito ao próximo, ou seja, a relação de consideração entre alunos e funcionários parece facilitar a convivência entre ambos, conforme trazido pelo grupo:

"Eu estou sempre falando com o pessoal da limpeza".

A percepção de tratar bem o próximo e o sentimento de entender a importância das tarefas de cada um dentro da organização é de interesse dos estudantes que relatam bem-estar quando tratam os funcionários com funções consideradas mais simples com respeito e valorização. Igue et al. (2008) destacam que o papel da universidade vai além de desenvolver atividades estritamente curriculares para o bom desempenho. Para os mesmos autores, no 
mesmo nível de relevância, está o desenvolvimento da competência interpessoal dos alunos e professores.

No segmento aluno-aluno, foram identificadas três categorias fáceis. A primeira categoria concerne à tolerância com as diferenças, à socialização e à aceitação para trabalhar com os colegas. Tais elementos remetem à busca de apoio mútuo entre os alunos e trazem em seu núcleo a necessidade de relações interpessoais adequadas aos objetivos acadêmicos comuns aos discentes, como aumento de produtividade e criação de um ambiente propício ao ensino e aprendizado. Esta questão é exemplificada na fala dos voluntários:

"Eu acho que é outra experiência rica da faculdade a gente ter contato com pessoas de diferentes classes sociais"

"Você entra na sala as pessoas sorriem para você, te tratam bem, te acolhem".

Além disso, os estudantes parecem entender que no contexto universitário é possível oportunizar encontros que facilitam adquirir conhecimentos e também se envolver em redes de amizades que ajudam nos relacionamentos entre os pares, garantindo, fortalecendo e estreitando os laços de amizade. Iturra et al. (2012) ressaltam que existe consenso entre os pesquisadores de que as relações, as atitudes e o bom repertório de habilidades sociais dentro do ambiente universitário podem desfazer situações conflitantes entre os estudantes.

Outra categoria foi responsabilidade e maturidade dos alunos que facilita os relacionamentos, conforme exemplificado na fala dos participantes:

"É uma responsabilidade. Não é só o seu futuro, tem o futuro de outras pessoas envolvidas".

Parece que essa atitude pode levar os estudantes a entender melhor as necessidades da outra pessoa e, desta forma, conseguem equilibrar as relações interpessoais. Como mencionado anteriormente, a universidade é responsável pela formação com qualidade de futuros profissionais, mas também por exercitar no cotidiano institucional a aprendizagem de habilidades sociais que extrapolem os limites da instituição. Coll e Collomina (1996) ressaltam que uma interação satisfatória pode ser medida pela qualidade dos relacionamentos em detrimento a sua quantidade. Portanto, as oportunidades de interação entre os iguais se tornam mais intensos à medida que melhoram a cooperação e as atitudes responsáveis, indispensáveis para boa comunicação.

A última categoria identificada foi redes sociais, que são entendidas pelos estudantes como um meio de se relacionar, isto é, como uma forma de viabilizar relacionamentos e facilitar àqueles que têm dificuldade em fazer amizades, como discutido no grupo:

"Facebook facilita porque você não tem que ficar olhando pra cara das pessoas. E você pode pensar mais no que você tá falando". 
Ferreira, Castro e Andrade (2011) verificaram na Universidade do Porto que o uso redes sociais virtuais para comunicação em sala de aula no Ensino Superior aumenta a participação dos alunos em atividades, uma vez que esses recursos digitais facilitam que os tímidos interajam com o outro, diminuindo os níveis de ansiedade presentes nos enfrentamentos das relações interpessoais ao vivo. Neste sentido, a utilização de tecnologias contribui para desenvolvimento do aprendizado dos estudantes, possibilitando que o aluno interaja com os conteúdos apresentados em sala de aula (Ferreira et al., 2011). As redes sociais também possibilitam aos estudantes organizarem movimentos sociais que visem ao exercício da cidadania em reivindicar seus direitos, promovendo encontros para refletirem sobre a sociedade em que vivem e traçarem planos de ação para negociar com representantes legais (Lamy, 2011). No entanto, para Z. A. P. Del Prette e A. Del Prette (2004), as redes sociais merecem ser vistas com parcimônia, pela possibilidade de causarem rupturas no contato social direto, na possibilidade de escassear as interações ao vivo e dificultar os contatos visuais e de carícias e, assim, deixar de promover e facilitar os relacionamentos. Para os mesmos autores, muitas vezes o contato pessoal pode facilitar a aproximação, com possibilidades de toques, afagos, sorrisos, elogios e abraços.

\section{CONSIDERAÇÕES FINAIS}

O estudo apresenta as percepções de estudantes de psicologia de uma universidade pública da cidade do Rio de Janeiro sobre as situações inerentes ao convívio interpessoal no Ensino Superior, que vão desde suas relações com o processo de aquisição do conhecimento e expectativas com a futura carreira, até o relacionamento com os demais colegas, professores e outros setores da instituição. Ao analisar as falas dos estudantes sobre seus conhecimentos acerca da percepção social e interpessoal na universidade, percebe-se que julgam estas situações como difíceis e fáceis no que tange à atividade dos professores, alunos, gestores e funcionários.

A análise indicou que as categorias selecionadas admitem perceber que de uma forma geral situações difíceis e fáceis estão presentes no ambiente universitário, reiterando outros estudos realizados na área. Os estudantes relatam informalmente que as situações sociais consideradas difíceis podem alterar o convívio e a aceitação entre as pessoas, causando impactos interpessoais entre os membros dos grupos, dificultando a comunicação e o diálogo entre os diversos setores da instituição. As situações de fácil convivência reforçam a ideia de que a competência social é condição indispensável na atuação dos profissionais que lidam diretamente com os universitários.

Os resultados também trazem a evidências de que as situações difíceis e fáceis são trazidas pelos estudantes para dialogarem a respeito das diferentes relações e especificidades no contexto universitário. Levando em consideração 
todos os dados apresentados, a pesquisa indica a necessidade de implantar ações junto aos gestores, professores, alunos e funcionários viabilizando momentos em que todos possam discutir e participar de forma mais organizada e produtiva nas interações da universidade. Silva (2012) ressalta a necessidade de estratégias que permitam a melhor adaptação e enfrentamento para as novas situações vivenciadas, auxiliando o estudante no autoconhecimento e manejo de situações difíceis. Neste sentido, comportamentos assertivos poderiam ser aprendidos através de Treinamento em Habilidades Sociais (THS). O THS possibilita desenvolver relações interpessoais e profissionais mais eficazes, além de promover a saúde física e mental, potencializando as capacidades dos participantes para o desenvolvimento de relações sociais mais aprimoradas e adequadas (Z. A. P. Del Prette \& A. Del Prette, 2010b; Caballo, 2008).

Pode-se apresentar como limitação o fato do estudo ter explorado dados apenas do curso de Psicologia de uma universidade pública, possuindo uma amostra restrita das ideias trazidas pelos estudantes desta área. É interessante propor um estudo que amplie as discussões para outros cursos e de outras instituições, a fim de garantir o envolvimento de novos estudantes na avaliação de situações vividas dentro da universidade. A relação interpessoal em qualquer especificidade requer uma boa convivência e para que essa seja satisfatória, é importante propor como perspectivas futuras o Treinamento das Habilidades Socais com estudantes universitários como uma forma preventiva e facilitadora para o manejo de situações difíceis encontradas na universidade.

\section{REFERÊNCIAS}

Associação Brasileira de Empresas de Pesquisa. (2015). Critério Brasil. Recuperado de http://www.abep.org.

Almeida, L. S., Soares, A. P. C., \& Ferreira, J. A. G. (2000). Transição e adaptação à universidade: Apresentação de um questionário de vivências acadêmicas. Psicologia, 16(2), 189-208. Recuperado de http://repositorium.sdum.uminho.pt/handle/1822/12069.

Antunes, C. (2001). Como desenvolver competências em sala de aula. Petrópolis: Vozes.

Backes, D. S., Colomé, J. S., Erdmann, R. H., \& Lunardi, V. L. (2011). Grupo focal como técnica de coleta e análise de dados em pesquisas qualitativas. O mundo da saúde, 35(4), 438-442. Recuperado de http://bvsms.saude.gov.br/bvs/artigos/grupo_focal_como_tecnica_coleta_a nalise_dados_pesquisa_qualitativa.pdf.

Bardin, L. (2009). Análise de conteúdo. Lisboa: Edições 70

Bariani, I. C. D. \& Pavani, R. (2008). Sala de aula na universidade: espaço de relações interpessoais e participação acadêmica. Estudos de Psicologia, 25(1), 67-75. doi: 10.1590/S0103-166X2008000100007. 
Barreto, M. C., Pierri, M., Del Prette, Z. A. P., \& Del Prette, A. (2004). Habilidades sociais entre jovens universitários: um estudo comparativo. Revista Matemática Estatística, 22(1), 31-42. Recuperado de http://jaguar.fcav.unesp.br/RME/fasciculos/v22/v22_n1/A3_MCMBarret_Al mir.pdf.

Bartholomeu, D., Nunes, C.H.S.S., \& Machado, A.A. (2008). Traços de personalidade e habilidades sociais em universitários. Psico-USF, 13(1), 4150. doi: $10.1590 / \mathrm{S} 1413-82712008000100006$

Brasil. (2003). Decreto de 20 de outubro de 2003: Institui Grupo de Trabalho Interministerial encarregado de analisar a situação atual e apresentar plano de ação visando a reestruturação, desenvolvimento e democratização das Instituições Federais de Ensino Superior - IFES. Brasília, DF: Diário Oficial da União. Recuperado de http://www.sintunesp.org.br/refuniv/GTInterministerial\%20-\%20Estudo.htm

Caballo, V.E. (2008). Manual de avaliação e treinamentos das habilidades sociais. São Paulo: Santos.

Carrara, K. \& Betetto, M. F. (2009). Formação ética para a cidadania: uma investigação de habilidades sociais medidas pelo inventário de habilidades sociais. Estudos de Psicologia, 26(3), 337-347. doi: 10.1590/S0103166X2009000300007

Coll, C. \& Colomina, R. (1996). Interação entre alunos e aprendizagem escolar. In C. Coll, J. Palacios, \& A. Marchesi (Orgs.), Desenvolvimento psicológico e educação (pp. 298-314). Porto Alegre, RS: Artes Médicas.

Cunha, S. M. \& Carrilho, D. M. (2005). O Processo de adaptação ao Ensino Superior e o rendimento acadêmico. Psicologia Escolar e Educacional, 9(2), 215-224. doi:10.1590/S1413-85572005000200004

Del Prette, A., Del Prette, Z.A.P., \& Branco, U. (1992). Competência social na formação do psicólogo. Paidéia: Cadernos de Educação, 2, 40-50. doi: 10.1590/S0103-863X1992000200005.

Del Prette, A., Del Prette, Z.A.P., Bandeira, M., Rios-Saldaña, M., Ulian, A., GerkCarneiro, E., Falcone, E., Barreto, M. \& Villa, M. (2004). Habilidades Sociais de Estudantes de Psicologia: Um Estudo Multicêntrico. Psicologia: Reflexão e Crítica, 17(3), 341-350. doi:10.1590/S0102-79722004000300007.

Del Prette, Z. A. P. \& Del Prette, A. (2004). Psicologia das relações interpessoais: Vivências para o trabalho em grupo ( $3^{a}$ ed.). Petropolis: Editora Vozes.

Del Prette, Z.A.P. \& Del Prette, A. (2010a). Habilidades sociais e análise do comportamento: Proximidade histórica e atualidades. Revista Perspectivas, 01(02), 104-115. Recuperado de http://www.uel.br/graduacao/odontologia/portal/pages/arquivos/nde/habili dades\%20sociais\%20e\%20an\%c3\%81lise\%20do\%20comportamento.pdf

Del Prette, Z.A.P. \& Del Prette, A. (2010b). Psicologia das relações interpessoais: Vivências para o trabalho em grupo ( $8^{\mathrm{a}}$ ed.). Petrópolis: Vozes. 
Fernandes, V.M.P. (2011). Adaptação académica e auto-eficácia em estudantes universitários do primeiro ciclo de estudos (Dissertaçãode Mestrado, Universidade Fernando Pessoa). Recuperado de http://bdigital.ufp.pt/bitstream/10284/2253/3/DM_15256.pdf

Ferreira, A. O. \& Souza, M. J. J. (2010). A redefinição do papel da escola e do professor na sociedade atual. Vértices, 12 (3), 165-175. Recuperado de http://essentiaeditora.iff.edu.br/index.php/vertices/article/view/18092667.20100028.

Ferreira, A. L. (2011). Psicologia e processos interativos nos espaços de periferia: a formação humana em questão. Recife: Universitária UFPE.

Ferreira, S. A., Castro, C., \& Andtrade, A. (2011). Morfologia da comunicação cognitiva 2.0 em sala de aula no âmbito do Ensino Superior. In Sexta Conferência Ibérica de Sistemas e Tecnologias de Informação (pp.294-300). Chaves, Portugal: Associação Ibérica de Sistemas e Tecnologias de Informação.

Gatti, B.A. (2005). Grupo focal na pesquisa em ciências sociais e humanas. Brasília: Liber Livro.

Gomes, G, \& Soares, A.B. (2013). Inteligência, habilidades sociais e expectativas acadêmicas no desempenho de estudantes universitários. Psicologia Reflexão e Crítica, 26(4), 780-789. doi: 10.1590/S010279722013000400019.

Gonçalves, J.P., Leite, A.F., Pavinato, M., \& Leite, T.Z. (2009). A interferência das relações interpessoais no processo de aprendizagem de alunos do ensino superior. In $V$ Encontro Paranaense de Pesquisa e Extensão em Ciências Sociais Aplicadas (pp. 2-13). Cascavel, Paraná, Brasil: Universidade Estadual do Oeste do Paraná.

Guimarães, S. E. \& Boruchovitch, E. (2004). O Estilo Motivacional do Professor e a Motivação Intrínseca dos Estudantes: Uma Perspectiva da Teoria da Autodeterminação. Psicologia: Reflexão e Crítica, 17(2), 143-150. doi: 10.1590/S0102-79722004000200002.

Igue, E. A., Bariani, I. C. D., \& Milanese, P. V. B. (2008). Vivências acadêmicas e expectativas de universitários ingressantes e concluintes. PsicoUSF, 13(2), 155-164. doi: 10.1590/S1413-82712008000200003.

Iturra, G. O., Goic, C. E., Astete, E. P., \& Jara, M. O. (2012). Habilidades Sociales y rendimento académico: Una mirada desde el género. Acta Colombiana de Psicología, 15(2), 21-28. Recuperado de http://www.scielo.org.co/scielo.php?script=sci_arttext\&pid=S012391552012000200003.

Kind, L. (2004). Notas para o trabalho com a técnica de grupos focais. Psicologia em Revista, 10(15), 124-136. Recuperado de http://www.pucminas.br/imagedb/documento/doc_dsc_nome_arqui200412 13115340.pdf. 
Lamy, C. (2011). Redes sociais: comunicação e mudança. Redes, 2(1), 73-96. Recuperado de http://observare.ual.pt/janus.net/images/stories/PDF/vol2_n1/pt/pt_vol2_n 1_art6.pdf.

Lener, R. M. (2011). Urie Bronfenbrenner: Contribuições da carreira de um cientista do desenvolvimento humano pleno. In U. Bronfenbrenner (Org), Bioecologia do desenvolvimento humano: Tornando os seres humanos mais humanos (pp.19-36). Porto Alegre: Artmed.

Pagotti, A. W. \& Pagotti, G. A. (2005). As Preocupações dos estudantes: Um estudo exploratório. Revista de Psicopedagogia, 22(68), 94-104. Recuperado de http://pepsic.bvsalud.org/pdf/psicoped/v22n68/v22n68a02.pdf.

Polydoro, S. A., Primi, R., Serpa, M. D., Zaroni, M. M., \& Pombal, K. C. (2001). Desenvolvimento de uma Escala de Integração ao Ensino Superior. PsicoUSF, 6(1), 11-17. doi: 10.1590/S1413-82712001000100003.

Salles, L. \& Silva, J. (2012). Diferenças, preconceitos e violência no âmbito escolar: algumas reflexões. Cadernos de Educação, 30, 149-166. Recuperado de http://www.periodicos.ufpel.edu.br/ojs2/index.php/caduc/article/view/1768 /1643.

Santos, C. P, \& Soares, S. R. (2011). Aprendizagem e relação professor-aluno na universidade: Duas faces da mesma moeda. Estudos em Avaliação Educacional, 22(49), 353-369. Recuperado de http://www.fcc.org.br/pesquisa/publicacoes/eae/arquivos/1641/1641.pdf.

Silva, L. (2010). As competências do servidor técnico-administrativo na reestruturação do ensino superior público: Estudo no Campus da Universidade Federal do Ceará no Cariri (Dissertação de Mestrado, Universidade Federal do Ceará). Recuperado de http://www.repositorio.ufc.br/bitstream/riufc/2801/1/2010_dis_LVCSilva. pdf.

Silva, E.C. (2012). Qualidade de vida e bem-estar subjetivo de estudantes universitários (Dissertação de Mestrado, Universidade Metodista de São Paulo). Recuperado de http://ibict.metodista.br/tedeSimplificado/tde_arquivos/2/TDE-2012-0313T161603Z-1069/Publico/Erika\%20Correia\%20Silva.pdf

Soares, A.B., \& Del Prette, Z.A.P. (2015). Habilidades sociais e adaptação à universidade: Convergências e divergências dos construtos. Análise Psicológica, 2(33), 139-151. doi: 10.14417/ap.911.

Teixeira, M. A. P., Dias, A. C. G., Wottrich, S. H., \& Oliveira, A. M. (2008). Adaptação à Universidade em jovens calouros. Psicologia Escolar e Educacional, 12(1), 158-202. doi: 10.1590/S1413-85572008000100013 
Yadzedjian, A., Purswell, K. E., Sevin, T. C., \& Towes, M. L. (2007). Adjusting to the first year of college: Students' perceptions of the importance of parental, peer, and institutional support. Journal of the first-year experience \& Students in Transition, 19(2), 29-46. Recuperado de http://eric.ed.gov/?id=EJ798197.

Sobre os autores

Adriana Benevides Soares é psicóloga, doutora pela Universidade de Paris XI e pós-doutora pela UFSCar. Atua como professora da Universidade Salgado de Oliveira (UNIVERSO) e da Universidade do Estado do Rio de Janeiro (UERJ). adribenevides@gmail.com.

Gil Gomes é psicólogo, mestre em Psicologia Social pela Universidade Salgado de Oliveira (UNIVERSO) e diretor do Instituto Brasileiro de Hipnose Aplicada (IBH). gil.gomes@globo.com.

Fátima de Almeida Maia é pedagoga da FAETEC, mestre e doutoranda em Psicologia Social pela Universidade Salgado de Oliveira (UNIVERSO). maiafalmeida@gmail.com.

Clystine Abram Oliveira Gomes é psicóloga, mestre em Psicologia Social pela Universidade Salgado de Oliveira (UNIVERSO) e Presidente do Instituto Brasileiro de Hipnose (IBH). clystinemestrado@gmail.com.

Marcia Cristina Monteiro é psicóloga, doutoranda em Psicologia Social pela Universidade Salgado de Oliveira (UNIVERSO) e professora da União das Instituições de Ensino de São Paulo (UNIESP) - Faculdade Duque de Caxias. marcia_lauria@yahoo.com.br.

Recebido em: 12/11/2015

$1^{\text {a }}$ revisão em: 08/03/2016

$2^{a}$ revisão em: 16/03/2016

Aceito em: 16/03/2016 